\title{
13 Stakeholder Perspectives on the Issue of Salinization in Agriculture in the Netherlands
}

Isa Camara Beauchampet

\section{CONTENTS}

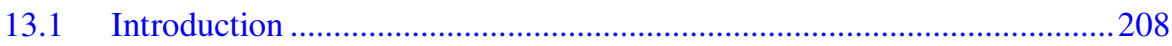

13.1.1 The Global Issue of Salinization................................................208

13.1.2 The Issue of Salinization in the Netherlands ..............................209

13.1.3 Problem Statement and Research Question ............................... 210

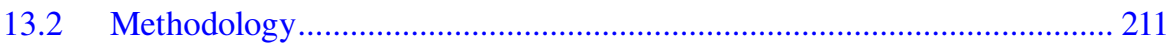

13.2.1 Theoretical Framework and Research Method ............................ 211

13.2.2 Data Collection and Analysis.................................................... 212

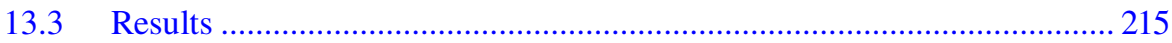

13.3.1 To What Extent Is Salinization Perceived as an Issue for Agriculture in the Netherlands? .............................................. 215

13.3.2 How Do Current Dominant Land- and Water-Management Practices Relate to Salinization? ……………………................. 216

13.3.3 What Are the Opportunities and Barriers to Different Mitigation and Adaptation Solutions in Addressing the Issue? ......................................................................... 219

13.3.3.1 The Parcel and Farm Level .......................................... 219

13.3.3.2 Community, Compartment, and Polder Level............. 221

13.3.3.3 Regional Water System (Waterboard Level) .............. 222

13.3.3.4 Provincial and Sub-National Level ..............................222

13.3.3.5 Main Water System and National Level......................223

13.3.4 What Locks-in the Status Quo and What Creates

Opportunities for (More) Salinization-Resilience? .......................223

13.3.4.1 Main Lock-ins of the Status Quo ...................................223

13.3.4.2 Main Opportunities for (More)

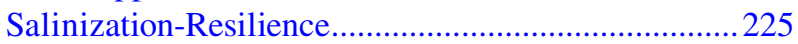

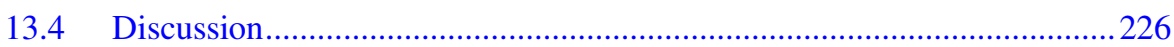

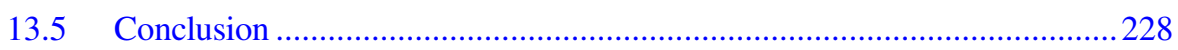

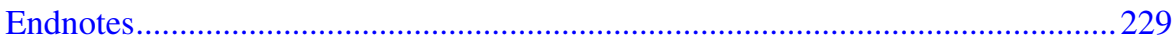

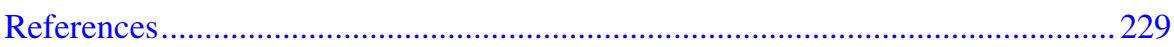

DOI: $10.1201 / 9781003112327-13 \quad \mathbf{2 0 7}$ 


\subsection{INTRODUCTION}

\subsubsection{The Global Issue of Salinization}

The salinization (i.e. increase in salt concentration) of fresh surface- and groundwater resources poses significant problems to farmers, industries, drinking water companies, and water managers in coastal areas all around the world (Delsman, 2015). These problems mostly relate to reduced crop yield, damaged infrastructure, adverse effects on vulnerable ecosystems, and the forced abandonment of extraction wells (Delsman, 2015). In addition, a combination of climatic and anthropogenic stresses like sea-level rise, changes in recharge and evaporation patterns, ground subsidence, population and economic growth, increasing industrial and agricultural water demands, and contamination of surface water further intensify pressures on freshwater resources and competition between the different uses in these areas (Figure 13.1) (Oude Essink et al., 2010).

With regards to agriculture, salinization of freshwater resources and agricultural land is one of the biggest threats to food production worldwide (Qadir et al., 2014), as higher salinity levels result in lower crop yields (Maas and Hoffman, 1977; Singh, 2015); furthermore, soil salinization is a global phenomenon, occurring in at least 75 countries, on more than 1 billion hectares of total land, and on $20 \%$ of irrigated land specifically (Ghassemi et al., 1995). Although recent statistics of the global extent of soil salinization do not exist (Shadid et al., 2018), Qadir et al. (2014) have estimated a daily expansion of this area by 2000 ha, and subsequent crop damage at 27.3 billion

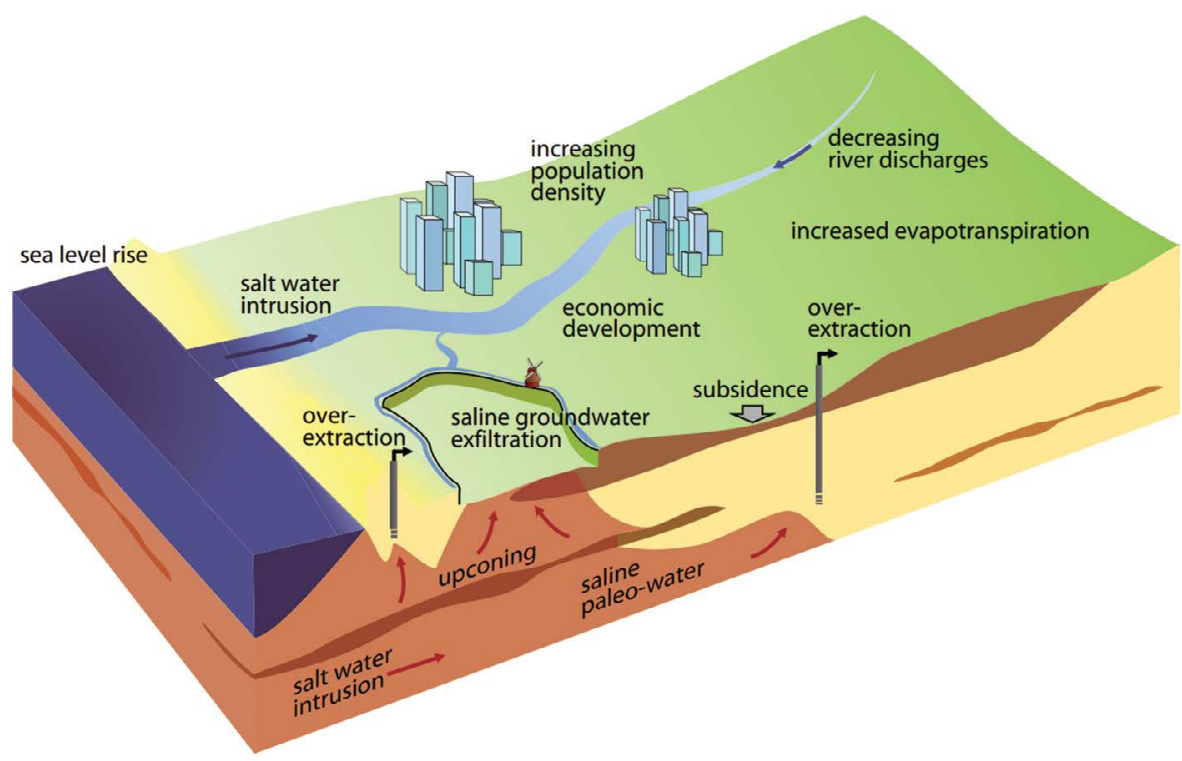

FIGURE 13.1 Overview of threats to coastal freshwater resources. (Reprinted from Deltares Select Series, 15, Delsman, J. R., Saline groundwater-Surface water interaction in coastal lowlands, 1-188, copyright (2015), with permission from IOS Press.) 
US Dollars a year (Qadir et al., 2014). The issue is becoming increasingly problematic and widespread, particularly due to climate change effects like sea-level rise and more frequent and severe droughts (Singh, 2015). In the worst cases, farmers have to abandon their fields and clear new arable land, adding pressure to natural ecosystems and biodiversity (de Vos et al., 2016), thereby affecting both livelihoods and the environment. With a growing population and subsequent growing demand for agricultural products, progressing climate change, little new productive land without sacrificing valuable nature, and increasing competition for freshwater resources, salinization is a global issue that urgently requires a solution (Qadir and Oster, 2004; Singh, 2015).

\subsubsection{The Issue Of Salinization in the Netherlands}

In the context of salinization, the Netherlands is rather unique for two reasons; firstly, about $25 \%$ of the land surface lies below mean sea level and without its dunes and dykes $65 \%$ of the country would be regularly flooded (Huisman et al., 1998), and secondly, a significant amount of the land surface $(600,000 \mathrm{ha})$ consists of polders, i.e. pieces of land that have been reclaimed from a body of water (i.e. a lake, floodplain or marsh) through the creation of artificial and autonomous hydrological systems of dykes and drainage canals (Huisman et al, 1998). In areas that lie below mean sea level, saline groundwater may reach the surface by upward groundwater flow, a process which is commonly referred to as saline or brackish seepage (Oude Essink et al., 2010). This results in the salinization of surface waters and shallow fresh groundwater bodies, making the water unfit for the supply of drinking water, industrial purposes, and irrigation (de Louw et al., 2010). In addition, brackish seepage can also directly end up in the root zone and thereby cause salt stress in plants (Oude Essink et al., 2010).

A future rise in sea level is expected to increase the seepage and salt loads in surface waters and thereby reduce the availability of both fresh surface water and groundwater (Oude Essink et al., 2010). Model simulations show that with sea-level rise, salt loads from groundwater seepage will be doubled in several low-lying parts of the coastal zone of the Netherlands by 2100 (Oude Essink et al., 2010). Moreover, as the low elevation of polder systems requires perpetual drainage of water to avoid waterlogging from seepage, both direct salinization (by attracting saline water to the surface) and indirect salinization (through ground subsidence) are already common (Oude Essink et al., 2010). Therefore, most of the salinization-prone areas are located near the coast, in reclaimed lands and in previous intertidal zones, where seawater is (historically) present in the groundwater and relatively close to the soil surface (Velstra et al., 2009; Figure 13.2). Without the use of freshwater to regularly flush through the water systems and soils in these low-lying areas, the brackish groundwater would be a major limiting factor to agriculture in particular (Velstra et al., 2009). However, the combination of increasing external intrusion of seawater in groundwater aquifers and (open) waterways, decreasing river discharge, decreasing precipitation and increasing evapotranspiration in the drier seasons is limiting the availability of freshwater to do this, especially at the 'end of the pipeline' regions (Velstra et al., 2009). 


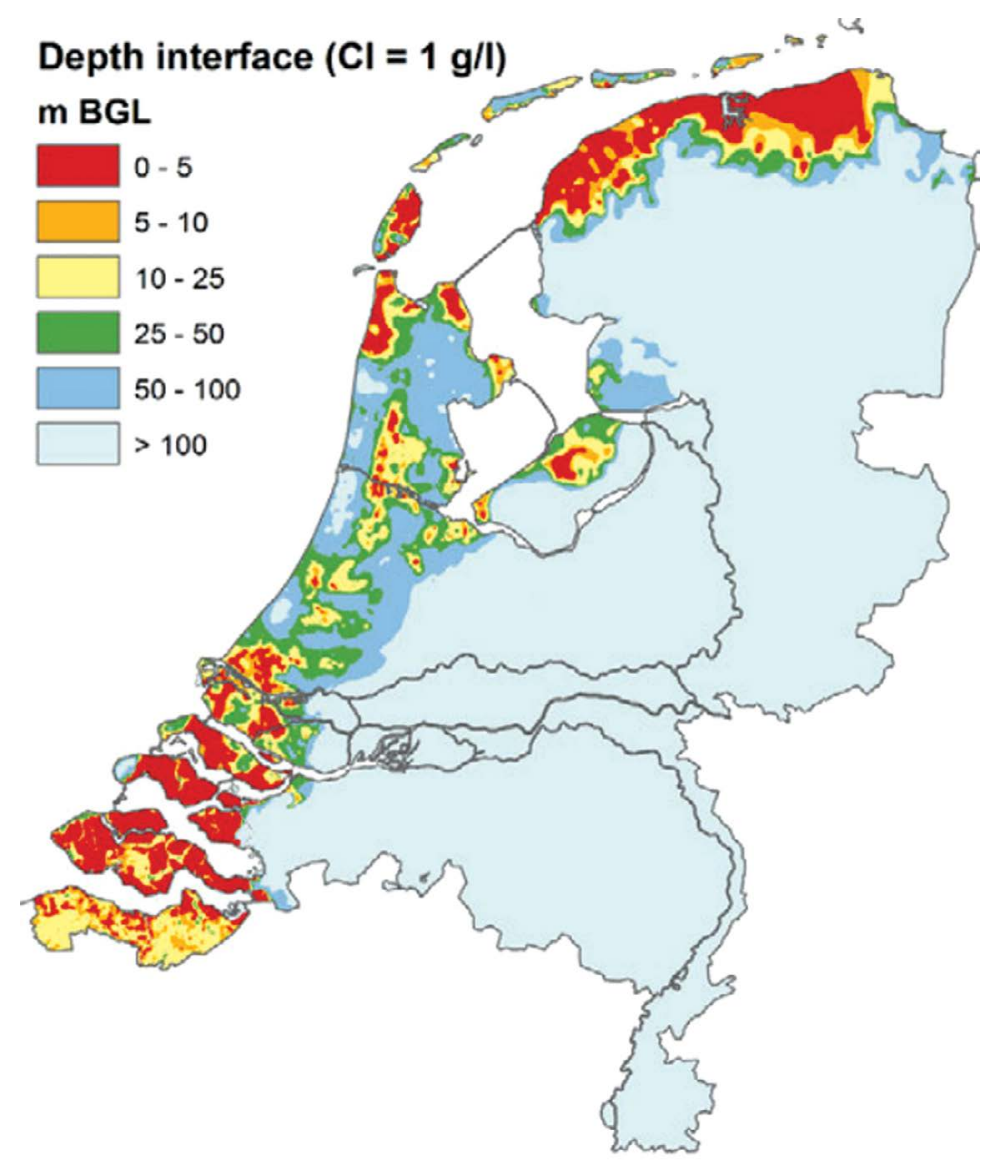

FIGURE 13.2 Depth of the fresh-salt interface in meters below the surface level, where 1 gram of chloride per litre is the concentration at which water is classified as saline in the Netherlands. (Source: de Louw, 2013.)

\subsubsection{Problem Statement and Research Question}

The threat of salinization in the low-lying coastal regions of the Netherlands is widespread and growing due to historically saline groundwater reservoirs, the relatively high (and increasing) sea level, ground subsidence, and changes in recharge and evapotranspiration patterns, which are not only accelerating salinization but also diminishing the supply and availability of freshwater (Velstra et al., 2009; Oude Essink et al., 2010). Agriculture in these areas is particularly vulnerable to the threat of salinization due to its exposure to brackish seepage from the sub-soils, weather events, and by being one of the last activities to receive freshwater in times of scarcity (OECD, 2014). Discovering how the Dutch agricultural sector can be made more salinization-resilient is of direct regional socio-economic importance as sensitive and intensive agriculture is especially located in salinization-prone areas (de Louw, 2013). Moreover, it can be of global importance as well since the Netherlands is one 
of the first deltas facing the impacts of climate change in combination with increased anthropogenic activities - due to the below sea-level position of, and high density of intense socio-economic activities in, the coastal region - thereby serving as a laboratory case for many other low-lying deltas around the world (Oude Essink et al., 2010).

However, as critical freshwater shortages have always been more of an exception to the rule - as evident from the national evaluations from water managers and users after the summer of 2018 which was the driest summer ever recorded in the Netherlands - the issue of salinization is relatively new to the Netherlands (Delta Commissioner, 2018a). Therefore, business-as-usual responses are rather unlikely to solve the problems ahead. On the contrary, new mitigation and adaptation measures are needed for 'climate-proofing' the freshwater availability in the Dutch delta, as evident from the recently established Delta Decision and Delta Plan on Freshwater Supply, which aim to secure the availability of freshwater now and in the future (Delta Commissioner, 2018b). In order to contribute to the overall knowledge gap of how the freshwater availability in the Netherlands can be made more climate-proof, this research aims to fill the gap of how the issue of salinization for agriculture in the low-lying Netherlands can be addressed. Therefore, the research question is: how can the Dutch agricultural sector be made more salinization-resilient? This will be answered through several sub-questions:

1. To what extent is salinization perceived as an issue for agriculture in the Netherlands?

2. How do current dominant land- and water-management practices relate to the issue of salinization?

3. What are the opportunities and barriers to different mitigation and adaptation measures in addressing the issue of salinization?

4. What is locking-in the status quo and what creates opportunities for a transition toward salinization-resilience'?

\subsection{METHODOLOGY}

\subsubsection{Theoretical Framework and Research Method}

The PRactice-Oriented Multi-level perspective on Innovation and Scaling (PROMIS) framework was applied to gain integrative perspectives on the scaling of salinization-resilient innovations for reducing the negative impacts of salinization. This framework connects the heuristic framework of the multi-level perspective on sociotechnical transition (MLP) to a 'modal aspects' framework, thereby enabling the heuristic exploration of relevant, multi-faceted dimensions and dynamics involved in innovation and scaling processes (Wigboldus et al., 2016). The application of the framework aided in unraveling the different dimensions of the current agricultural and water-management system that keep it from becoming more sustainable and that affect the scaling of more sustainable technologies, practices, and policies (Wigboldus et al., 2016). Moreover, it helped to identify how a variety of dynamics in scaling interact, thereby locking current practice into its unsustainable mode or stimulating change (Wigboldus et al., 2016; Figure 13.3). 


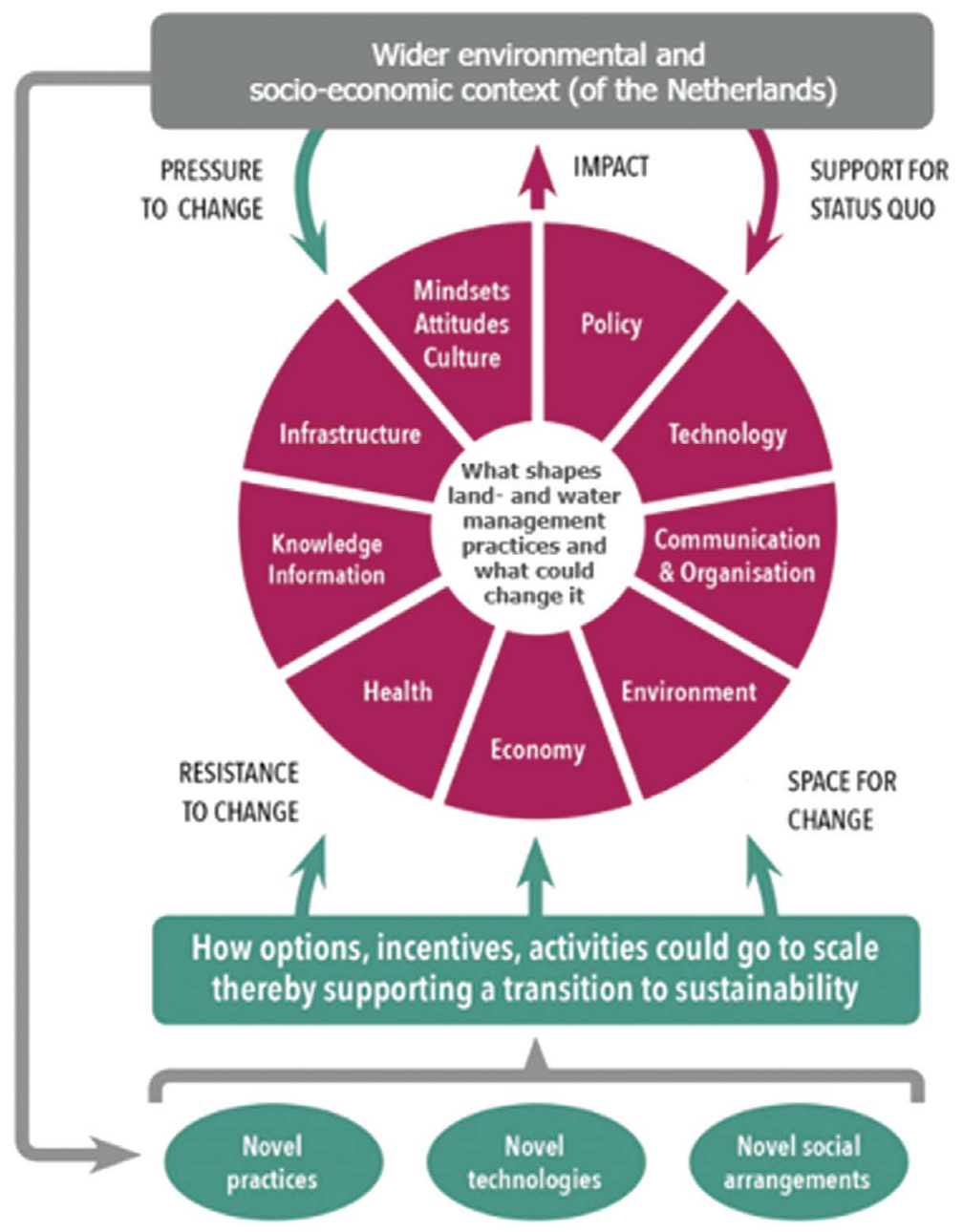

Emerging from e.g. farmer initiatives, research and development, government policies

FIGURE 13.3 An integrative perspective on multi-level dynamics that have implications for opportunities to make a transition to a more salinization-resilient agricultural sector. (Adapted from Wigboldus et al., 2017.)

\subsubsection{Data Collection and Analysis}

Semi-structured interviews were held with stakeholders to ensure that a large range of dimensions and dynamics relevant to the scaling of salinization-resilient measures were able to emerge. This was especially important, considering that little peer-reviewed literature on the issue of salinization and (innovative) salinization-resilient measures existed to inform which specific aspects should be reviewed by the interviewees.

For the selection of stakeholders, Reed et al.'s (2009, p.1933) definition of a stakeholder as someone who is 'affected by the decisions and actions [that are taken], and 
who has the power to influence the outcome' was applied. Under this broad definition, agricultural businesses, waterboards, and provinces, and any other individual or organization that has the power to influence the issue of salinization could be included. To ensure a wide range of explored perspectives and interests, interviewees (50 in total) were selected from each salinization-prone province, with a balance between interviewees from both the niche level and the regime level, as well as between private and public stakeholders.

For the expert interviews, 12 Dutch experts in the field of salinization and/or salinization-resilient measures were selected. These scholars were mostly identified from the literature review and were selected on the basis of their evident expertise, i.e. either having published multiple papers on the topic and/or being referred to as an expert by the research institute they are connected to. Several experts were selected on the basis of referrals, as these were practical experts (e.g. advisors) instead of scholars. Experts were incorporated in the research for their relatively objective and/ or nonpartisan evaluation of the issue of salinization and possible solutions, as compared to stakeholders.

For the stakeholder interviews, officials from six provinces and seven waterboards in salinization-prone areas were interviewed. All relevant provinces and waterboards were included to ensure that relevant regional differences like the dominant type of soils (e.g. clay or sand), agriculture (e.g. arable farming or horticulture), and water supply (e.g. presence of a river body or not) were accounted for. The experiences and perspectives of agricultural stakeholders (i.e. farmers) were represented by the farmer network organizations (12 representatives in total), as these were most aware of the current situation and issues in the sector and could thus provide an overview of the perspectives of most farmers. Furthermore, nine farmers that were experimenting with salinization-resilient measures were interviewed, as these represent the niche level and could thus identify the relevant factors and dynamics that allow or prevent the scaling of these measures. Furthermore, three plant breeders were interviewed to discover whether and how they incorporated salt-tolerance since this could tell something about the demand for and feasibility of breeding on the basis of salttolerance. Finally, two national governmental bodies were interviewed as well since these are also involved in the issue of salinization, mainly through coordination, legislation, and funding. Most stakeholders were identified through google searches and snowballing, i.e. selecting through the referrals of those that are interviewed already (Reed et al., 2009). The list of the interviewees can be found in Table 13.1.

The face-to-face interviews were recorded and transcribed afterward; the interviews over the phone were transcribed on the spot. The analysis of the transcriptions was done by identifying the overarching, categories, concepts, and patterns. The aspects of experienced reality from Table 13.2 were used to guide the process to ensure coherence and completeness. The subsequent emerging themes were then analyzed by use of the PROMIS framework, and categorized into the niche, regime and landscape level, including the interactions between them, and the lock-ins of the current nonsalinization resilient practices; the opportunities for (more) salinization-resilience were also identified. Due to the large quantity of interviewees, the results are supported by use of a scale of how often a statement, opinion, or view emerged from the interview data, i.e. few (<3), some (4-9), many (10-19), majority (20-34), nearly all (>35). ${ }^{2}$ 


\section{TABLE 13.1 \\ List of Interviewees}

\section{Category \\ Agro-hydrological experts}

Agricultural experts

Plant breeders

Provinces

Waterboards

Central government bodies

Agricultural network organizations

Innovative farmers

\section{Organization or Specialization}

Wageningen University

Acacia Water

Deltares

STOWA

Wageningen University

Salt Farm Texel (2x)

SPNA

Delphy (flower bulbs (3x), Zeeland, and South-Holland)

Agrifirm

Agrico Research

HZPC

C. Meijer B.V.

Groningen

Friesland

North-Holland

South-Holland

Zeeland

Flevoland

Noorderzijlvest

Fryslân

Hollands Noorderkwartier

Rijnland

Hollandse Delta

Scheldestromen

Zuiderzeeland

Rijkswaterstaat

Ministry of Infrastructure and Water Management

LTO North (Friesland and Groningen) 2x

LTO North-Holland

LTO South-Holland

ZLTO Tholen

ZLTO Zeeland

LTO Flevoland

Greenport North-Holland Noord

Greenport Boskoop

Royal General Union for Flower bulb culture (KAVB)

Water Commission Northern Sand Region

Zeeland (5x): saline agriculture and freshwater measures at parcel, community, and regional level

North-Holland (2x): freshwater measures parcel

Groningen: freshwater measures parcel

Friesland: freshwater measures parcel 


\section{TABLE 13.2 \\ Aspects of Experienced Reality That Can in Various Ways Be Affected by, or Affect, Innovation and Scaling Processes}

\section{Categories of \\ Experienced Reality}

Natural and physical capital
Aspects of

Experienced Reality

Quantitative, spatial, kinematic, physical

Biotic, sensitive

Human capital

Biotic, sensitive

Analytical-logical

Formative

Social and financial Lingual, social capital
Cultural, political and Juridical moral capital
Example of Entities That Distinguish Themselves from

Other Entities Primarily along the Lines of That Aspect

Numbers, location, atmosphere, climate, water, soil, natural forces, chemistry, transportation, infrastructure, buildings, equipment

Plants, animals, birds, fish, organic processes, ecosystem, biodiversity, forest, desert, habitat, farm, crops, livestock, animal behavior

Awareness, health, physical and mental abilities, emotion, personality, disposition, passion, observation, population dynamics, safety

Knowledge, theory, logic, conceptual framework, science, research, education

Construction, creativity, skill, computer software, design, power (in relationship): technology, strategy, methodology, innovation, adaptation

Symbols, signs, language, communication, information, media

Relationships, roles, social cohesion, competition, collaboration, organisation, societies, alliances, partnerships

Resource management, conservation, stewardship, exchange of goods and services, transactions, efficiency, sustainability, economy, land use, market, value chain, firm, employment

Rights, law, responsibility, appropriateness, policy, legal system, constitution, mandate, police, the state, democracy, ownership

Aesthetical, ethical, certitudinal
Appeal, beauty, enjoyment, leisure, sports, art Attitude, care, sharing, goodwill, integrity, equity, being right, solidarity identity, belief, trust, faith, vision, commitment, aspiration, worldview, ideology, paradigm

Source: Adapted and Abbreviated from Wigboldus et al., 2016.

\subsection{RESULTS}

\subsubsection{To What Extent Is Salinization Perceived as an Issue for Agriculture in the Netherlands?}

Although all interviewees recognize that salinization is largely harmful to agriculture, the exact extent to which it is or will be harmful is difficult to determine because of several reasons (majority). Firstly, salt stress and drought stress look very 
similar and predominantly appear at the same time since saline water can reach the surface in dry periods (majority). Secondly, (the risk of) diffuse brackish seepage is largely invisible to farmers as the conditions within the parcel of land cannot be easily observed (many). Thirdly, the threat of salinization and salt-damage depends on many different cultivation specific factors (majority), like the cultivated crop (i.e. length of roots, growth stage at time of exposure, salt-tolerance), soil type, soil quality, thickness of the freshwater lens, the type of drainage, and can therefore differ per parcel and even within a parcel. Fourthly, salinization is not a linear process, it comes in peaks and fluctuates per season and year (majority). Fifthly, the effect of different salt concentrations on commonly cultivated crops and soils other than sand are largely unknown (nearly all). Sixthly, salinization risk maps cannot be directly extrapolated to the parcel level, nor estimate actual damage (many).

The complex nature of salinization could explain why, although there are many regions with a risk of salinization and although last year was recognized to be exceptionally dry, there are not that many signs nor reporting of widespread salinizationrelated issues or damage yet (majority). Another explanation could be that the issue has not been identified as such yet by farmers as it is not common practice to measure the salt concentrations of parcels and irrigation water (many). Moreover, it is rather difficult to establish maximum possible yield and to link sub-optimal yield to just one factor like salinization (many). Few, argue that the low reporting of salinization problems is the result of the issue being a taboo, e.g. as salinized lands drop significantly in financial value once discovered. Either way, there is a consensus that there is very much an awareness issue, i.e. that the threat and issue of salinization are not being recognized and/or acknowledged.

Although the issue has become more prominent in recent years and is starting to become more and more of a concern amongst farmers and (to a lesser extent) policy-makers due to climate change and especially the exceptionally dry summer of 2018 (majority), there is still a lack of urgency because: (1) the issue is only little or just recently starting to be experienced, recognized and/or signaled by farmers (majority), (2) the damage has not been significant enough yet (majority), and (3) it is relatively low on the priority list of current pressing issues in the agricultural sector, like droughts, flooding, nutrients, biodiversity, etc. both from the perspective of policy-makers as for farmers (majority).

It is generally recognized that it will take more dry periods - like the year 2018 - to make salinization into a prominent theme (majority). The majority of the interviewees, expect the latter to happen sooner or later as salinization will become more and more of a problem, mostly due to autonomous salinization, sea-level rise, decreased river runoff, and decreased precipitation and increased evapotranspiration during the summer months - although the exact extent of the issue in the future is uncertain as this is largely determined by how climate change will develop.

\subsubsection{How Do Current Dominant Land- and Water- Management Practices Relate to Salinization?}

In general, it is recognized that many of the current dominant agricultural landand water-management practices are contributing to salinization. As recognized by 
nearly all interviewees, the regime of the past decades has been to dispose of freshwater as much as possible, since without it these regions would be flooded due to their position beneath sea-level (many), but also because floods have been, and to a large extent still are, more common and impactful (majority). In line with this regime, the dominant drainage method amongst farmers is conventional drainage in which water is continuously drained until the water-table is lowered to a certain depth (nearly all). This method, however, does not ensure that freshwater is retained for periods in which it is necessary (majority), as it ensures that soils continue to be drained to a certain depth, and as it drains the fresh precipitation water instead of saline groundwater, thereby drawing saline groundwater to the (sub-)surface in drier periods, possibly salinizing the root zone. The reason that this is still the dominant method of draining is because: (1) it is the customary practice, i.e. farmers do not know any better (many), (2) it is rather unproblematic in 'normal' years (many), (3) farmers are more focused on removing water instead of retaining it, for example because heavy rains are more common and impactful than drought or salinization (majority), (4) farmers are not that aware of a freshwater lens (some), (5) farmers do not know or do not acknowledge that this type of drainage can cause salinization or contribute to their drought problems (many), and (6) other drainage systems are more expensive (majority).

Another preference amongst farmers is that the water level in their parcel and their region is kept as low as possible to lower the risk of flooding during heavy rains and for them to be able to work on their fields with heavy machinery (nearly all). However, the water level in their parcels is determined by the water level in the ditches, and in turn determined by the compartment water level, which is a legal agreement between the farmers and the waterboards (many). Therefore, many farmers have installed so-called under-drainage with which they can artificially lower the water level beneath that of the regional system, whereas this also increases the risk of saline seepage (some). Next to the parcels being designed to drain as much water as possible, the intensification of cultivation practices over the past decades has led to the large-scale deterioration of the structure and fertility of soils, which are therefore not capable of draining large quantities of rainfall during heavy precipitation events, nor retaining freshwater when it is drier (many). The latter also results in an increased risk of salinization, since saline groundwater can more easily reach the root zone if the soils are dry (many). In regions where farmers use deep freshwater lenses to irrigate because no fresh surface water is available, there is a risk of exhausting and/or salinizing these wells, since sustainable extraction is difficult for farmers and local water managers to determine and control (some).

Due to the historical function of regional water systems (many) - and sometimes also the technological inabilities and lack of freshwater in the surrounding areas at the time which restricted a supply function (some) - most regional water systems have been historically designed to dispose of water instead of retaining or supplying areas with water (many). Next to lacking the ability to retain water, another consequence of this historical function and design is that most systems do not have separate discharge and supply channels, and/or that these are often not located in the right places. This results in the inefficient flushing of the system, i.e. large variation in chloride levels between ditches, and the general water quality being lower than it 
could be due to the mixing of fresh and saline water (many). The regional water systems that have been designed for flushing and the supply of freshwater are often the locations where more sensitive high-capital cultivations like flower bulbs have been historically located or where they start to emerge (many). The paradoxical situation of high-capital and high-quality water demanding crops being located in the most salinization-prone areas is a widespread phenomenon (many), mostly explained by the fact that the soils here are very suitable to these types of cultivations (many), that the distribution infrastructure is already there (some), and in some cases - especially flower bulbs - also because of the fact that there is a secured freshwater supply for flushing (some). However, the facilitation of high-quality freshwater demanding cultivations in largely salinization-prone areas results in significant challenges for waterboards during dry periods and might become too technically challenging and costly in the future (many).

The challenge that waterboards face of having to keep the water supply fresh mostly relates to there being 'effort obligations' of chloride norms they have to adhere to for flushing (many), though these norms are quite arbitrary and it is difficult to determine at what point the effort a waterboard has to take is no longer 'reasonable' (many). Moreover, as the waterboards are in charge of the regional water system and therefore responsible for the water quality in the ditches, farmers tend to pressure them into adhering to the norms (many). The latter is also the result of farmers being largely dependent on this collective service, as they have never invested in water retaining measures or their own water storage since the disposal, supply, and quality management of water have been arranged collectively in the Netherlands ever since the waterboards were established (many). Therefore, although several waterboards state their historical function has changed and that they are not legally obligated to supply farmers with enough freshwater at all costs, the practical reality is that they do go to great lengths to make it possible (many). On top of that, most farmers believe this should actually be the case because they pay waterboard taxes and as they think freshwater availability should be, or is best to be, arranged collectively (many). What is adding to this challenge is the fact that although the function an area gets - e.g. agriculture, residential area, nature - should be based on the water situation according to the waterboards and provinces, this is currently not yet the case in provincial spatial planning policies, implying that high-quality water demanding types of agriculture can settle in salinization-prone areas and that waterboards will have to facilitate these to the best of their ability (many). The latter is also the result of this spatial classification being rather broad, i.e. not differentiating between different types of agriculture (some).

Another dominant water-management practice at a higher management level that is perceived as unsustainable - especially by agricultural stakeholders but also by several waterboards and provinces - is the fact that the majority of freshwater that is entering the country is immediately being discharged into the North Sea (many). Although this is not much of an issue in 'normal' years, it can be an issue during dry summers when river discharge is low and much more water is needed to counterpressure the salt wedge from entering the main waterways (some). This is where the different functions of the main waterways and inlet points start to collide, i.e. the shipping sector profits from the open connection to the sea at the Nieuwe Waterweg, 
whereas this increases the salt load in the main rivers to the point where the salt concentrations near the inlet points of the regional water systems can become too high for drinking water and industry, resulting in water shortages for agriculture in the area behind the inlet point as well (some). When this happens, the so-called climateproof waterway which directs water from the IJsselmeer and the east of the country directly to the west via an alternative route, is expected to become the rule rather than the exception due to climate change (some). In addition, the IJsselmeer is seen as an important water buffer by the adjacent provinces and there will be increased competition between the different regions for using this source in the future if the supply of river water to it and/or its buffering capacity is not increased (many).

Farmers cope with salinization of freshwater for irrigation in various ways (majority); it depends on the crop they cultivate (i.e. sensitive flower bulb versus relatively tolerant sugar beet), the chloride/EC levels they are used to, their practical experience, their risk perception, the soil type, the quality of the crop or yield (the poorer, the more they are willing to take the risk), the growth stage of their crop (seedlings can take less), the time in the season (if it is at the beginning or the end of the growing cycle, do they expect rain or not), and so on. Therefore, there are large discrepancies between what different arable farmers, vegetable farmers, and flower bulb growers perceive as 'too saline' for irrigation - even between different regions - and also between what they do and what scientific experiments have determined what is possible, both positively and negatively (many). Nearly all interviewees state that it is largely uncertain what the salt tolerances of commonly cultivated crops and soils are and that farmers, therefore, maintain a conservative standard, especially considering the large financial risk they would be taking (many). This also implies that there are hardly any field measurements of the effect of different salt concentrations on crop yield (some), whereas raising these norms could potentially limit drought damage by increasing the amount of usable water in times of drought (some).

\subsubsection{What Are the Opportunities and Barriers to Different Mitigation and Adaptation Solutions in Addressing the Issue?}

\subsubsection{The Parcel and Farm Level}

Nearly all interviewees recognize that, at the parcel and farm level, salinizationresilience can be increased in the short- and medium-term by increasing the freshwater lens in the parcel. The majority of the interviewees see a large role for levelcontrolled drainage or so-called anti-salinization drainage in preventing soil and root zone salinization by conserving and even enlarging the freshwater lenses in the soils. Projects like Spaarwater in the northern regions of the Netherlands and the pilots in Zeeland are therefore perceived to be of great importance in researching what is possible but also in demonstrating to farmers what the positive effects of these alternative types of drainages are (majority). By buffering freshwater in the sub-soil, farmers simultaneously lower the risk of drought and salinization (many). Moreover, as these alternative measures are similar to what farmers are already used to, it is more attractive to make the switch (some). The complexity with anti-salinization drainage, however, is that it has to be carefully customized since the thickness of the freshwater lens is very parcel specific and can even differ within a parcel, and 
as soil structure matters as well (many). An obstacle to installing level-controlled or anti-salinization drains, in general, is that drains are installed only once every 20 years and that it is uncertain whether this more expensive investment is profitable since farmers cannot foresee how much they will suffer from salinization or droughts in the future (some). There is also the confusion/perception amongst farmers that increasing the freshwater lens through drainage can result in a wetter environment and a higher risk of flooding, which hampers the implementation of these types of drainage as well (some). Another obstacle to these systems is that they still rely on the availability of freshwater, as they can still run dry and/or because setting up the water in the drains with saline water is not desirable (some). An opportunity to further increase the freshwater lens by use of innovative drainage is by combining it with water infiltration in the sub-soil (some). Nevertheless, freshwater infiltration into the freshwater lens or deeper aquifer is not always possible and currently not allowed due to regulations on preventing groundwater contamination (some).

Another way farmers can increase the freshwater lens in their parcels quite easily is by more shallow dewatering, or by increasing the water level underneath the parcel by keeping the water up in their ditches with (simple) weirs (some). Nevertheless, barriers are that most farmers are more fearful of flooding or not being able to work their fields with heavy machinery (many) and because they think that setting up brackish water in the ditch might increase the brackish seepage in their parcel (some). The latter interaction is contested by what farmers do on Texel, where they set up the water early in the year already to keep the freshwater in their parcels, despite the water in the ditches being brackish or even saline (some). Another low-hanging-fruit for farmers with brackish ditches is to install weirs that separate and subsequently dispose of the brackish water and retain the freshwater - a rather simple and costeffective measure (some). Nevertheless, this measure is not widely implemented yet, arguably since people were, or still are, unaware of the water stratification in ditches (some). Next to conserving and enlarging the freshwater lens, there are different lowinvestment measures which can improve the structure and fertility of the soil in order to retain more water and be more drought, salinization, and even flooding resilient; these include zero-tillage, supplying more organic matter, and the cultivation and use of green manure (some). However, it is rather unknown how farmers can do it most effectively (some).

Another yet uncommon practice which could lower the risk of salt stress and drought stress is the more economical use of freshwater through sub-soil drip irrigation or similar methods (some). However, the cost-effectiveness of such measures depends on whether, and how much, one has to irrigate as these systems are costly and time-consuming to install and only last for a (couple of) year(s) (some). Moreover, as drip irrigation is quite expensive, it is seen as being more suited to highvalue cultivations (some). Nevertheless, even without investing in different types of irrigation, there is already much efficiency to gain with conventional irrigation by irrigating on the basis of data instead of experience/intuition - the latter still being the dominant basis of decision-making (some).

Next to the different mitigation measures at the parcel level, adaptation to brackish circumstances, i.e. (more) salt-tolerant agriculture, is also a strategy that can be considered. However, currently available research on crop salt-tolerance is rather 
old, is for different crops/cultivars to those that are common in the Netherlands, was conducted under a different climate, and on different soils (i.e. mostly sand), and is therefore considered to be of no or little use in the Netherlands (many). This also means that the exact effect of salt on crop yield is largely uncertain and that current norms used by farmers are largely based on a limited knowledge base, rough estimates, and/or intuition (many). Although it is recognized by the majority of the interviewees that it is desirable to have more research on this - especially on peak salt events and salt tolerance at different growth stages as crops are often exposed to salinization at specific moments - the main question is who should and would pay for this.

Furthermore, according to the potato breeders, it is really difficult to determine salt-tolerance, as there are large differences between the results from tests in the greenhouses (in controlled environments) and tests in the field - where the variations in results tend to be large, poorly repeatable, and rather unpredictable. Moreover, breeding takes a long time, and although research on the genetics that determines salt-tolerance can speed up this process, this is rather complicated and time-consuming as well. Another complicating factor in adapting to more brackish conditions is that farmers have to apply crop rotation and that there are large variations between the salt tolerance bandwidths of these crops, e.g. seed potato is sensitive, whereas sugar beet is rather resilient (some). Nevertheless, knowing the salt tolerance of different cultivars would help in making a more informed decision on whether to irrigate with more brackish water or not, and/or what crop/cultivar a farmer might be able to switch to (many).

However, even though a crop might be or might become more tolerant, this cannot compensate for the fact that, in general, salts affect the structure of soils, thereby resulting in lower yields as well (many). Nevertheless, it is recognized that it is largely uncertain at which threshold salt concentrations become too high for effective cultivation on clay, and also what one can use gypsum, green manure, and/or organic matter to compensate for the negative effect until that threshold is reached (many). Therefore, it is recognized that (large-scale) field experiments on clay are desirable to establish this and provide action perspectives for farmers (many), although so far it has been very difficult to get government funding for this, arguably because of a lack of urgency and interest (some). Finally, nearly all interviewees do not see halophyte or 'saline crops' as part of the solution, mostly due to lacking markets, the intolerance of soils, and the manual work they require. Furthermore, at least in the short- to medium-term, some see it is as less complicated to resist salinization from happening than to effectively adapt to it. Nevertheless, researching the salt tolerance of 'cash crops' and especially cultivars that are already marketed is seen as contributing to salinization-resilience (many).

\subsubsection{Community, Compartment, and Polder Level}

At the community, compartment, and polder level, freshwater can be retained through the use of weirs (some). Using so-called 'fresh' or 'smart weirs' like they do on Texel can also result in the freshening of the surface water of an entire compartment or even polder, as the brackish water is disposed of while the freshwater is retained $(f e w)$. Furthermore, saline channels and ditches could be separated from the 
supply channels, and/or saline ditches could be closed off from the system to make flushing more efficient, but often waterboards are not aware of chloride differences at such detail (some). At the compartment level, the waterboard can retain water longer by (seasonally) raising and maintaining the water level, which also counterpressures saline groundwater, thereby lowering the risk of saline seepage (some). However, raising the water level in a water level compartment is not simple as there is a legally bounding agreement between the farmers and the waterboard. Therefore, if part of the community wants the water level to be raised, everyone has to agree with it; if only one disagrees then it has to be adhered to again (some). The latter can be very difficult as there are often conflicting interests, e.g. one farmer wants the water-table to be low in order to cultivate the land, whereas another needs the water for their crops (some). Moreover, if it goes wrong, especially because a higher level can increase the risk of flooding, the waterboard might be held accountable by the farmers (some).

\subsubsection{Regional Water System (Waterboard Level)}

At the regional water system level, i.e. the waterboard, there is still some efficiency in flushing to be gained, e.g. by redesigning waterways, separating saline and fresh waterways, but also through more data-driven operations, as currently most of the operations are based on human decisions rather than measurements and forecasting (some). Furthermore, the chloride norms waterboards have to adhere to could become more area-specific, taking into account the variations in salt loads in different parts of the regional system and the ability to flush it through (some). In terms of raising the norms of inlet points, there is very little they can do, as often more functions depend on this norm (some).

Another (drastic) measure would be to differentiate the price farmers pay on the basis of their location in the system and/or even their extractions (some), as is currently the case in just one region, namely Tholen and St Philipsland in Zeeland. Nevertheless, the majority of the farmers prefer such water systems to be paid collectively, as according to them: (1) everyone profits from a 'fresh environment', (2) there are still costs even without extraction, and (3) a price incentive could result in only the farmers that have to irrigate carrying the burden of the system (few). This is an example of the dominant (historical) perception that arranging water supply and quality collectively is less expensive, more effective, and therefore more preferable than farmers paying a (full) users' fee or becoming (completely) self-sufficient (many). This is further supported by the fact that although waterboards and provinces generally promote self-sufficiency and think it is important that farmers take their responsibility in the issue, they also state that flushing is actually not that expensive whereas many self-sufficiency measures are not nearly cost-effective (many), exposing a tension between the distribution of societal costs and benefits.

\subsubsection{Provincial and Sub-National Level}

At the provincial level, both the interviewees from the waterboards as well as the provinces agree that the function assignment of an area should be based on the water situation, i.e. what would be the current ability of a waterboard to provide that region with freshwater of a certain quality, as well as its future ability based on salinization 
projections (many). Until now, this has not been the case, mainly because: (1) provinces are in charge of spatial planning policies whereas waterboards are in charge of the surface water management (many), and (2) salinization has not been a significant bottleneck so far (some), (3) the current water situation and projections of salinization have not been (sufficiently) mapped out ( $f e w)$, and (4) there are many other factors that a province has to take into account when assigning spatial functions $(f e w)$. In the future, functions could be changed as an adaptation measure when it becomes too (societally) costly to facilitate certain functions in specific areas and to ensure that there is still enough freshwater of sufficient quality for regions where it is not too costly (many). This should also preferably include differentiation between different types of agriculture - e.g. differentiation between livestock, flower bulbs, arable crops, based on a reasonable chloride norm (some). However, such function differentiations are perceived to be politically difficult since it could come across as prescribing businesses what they should do, although in theory, it only determines what functions are actively being facilitated (some). Nevertheless, several experts, agricultural stakeholders, and governmental advisors agree that it will be impossible to facilitate freshwater agriculture everywhere in the future (many).

\subsubsection{Main Water System and National Level}

As previously discussed, some think the current distribution of the freshwater that is entering the main water system could be changed in order to supply more areas with sufficient freshwater for flushing and to increase the buffer capacity of freshwater bodies like the Volkerak-Zoommeer (which is actually still planned to become brackish for nature), Haringvliet (of which part of the sluice is left open intentionally to allow fish migration), and IJsselmeer (which is used by six provinces). Especially the external salinization at the Nieuwe Waterweg, which is in open connection to the sea for the benefits of the shipping sector, is criticized, as most of the freshwater entering the country is used on counter-pressuring the salt wedge, while still not being able to completely prevent salinization of important inlet points (some). Moreover, salt water enters the regional and main water system during the locking for ships, meaning that different economic considerations have to be made during times of increasing salt loads and decreasing river discharge (some). Although several changes to the infrastructure of the main water system are possible, they are often still not effective in the long-term and/or not cost-effective, e.g. because the shipping sector is affected by it and its economic interest tends to be larger than that of the agricultural sector $(f e w)$.

\subsubsection{What Locks-in the Status Quo and What Creates Opportunities for (More) Salinization-Resilience?}

\subsubsection{Main Lock-ins of the Status Quo}

The main lock-ins of the current status quo and the opportunities for a transition toward salinization-resilience which emerged from the interviews are summarized in Figure 13.4. Currently, the majority of experts and stakeholders share the notion that a sense of urgency is lacking for addressing the issue of salinization, mostly 


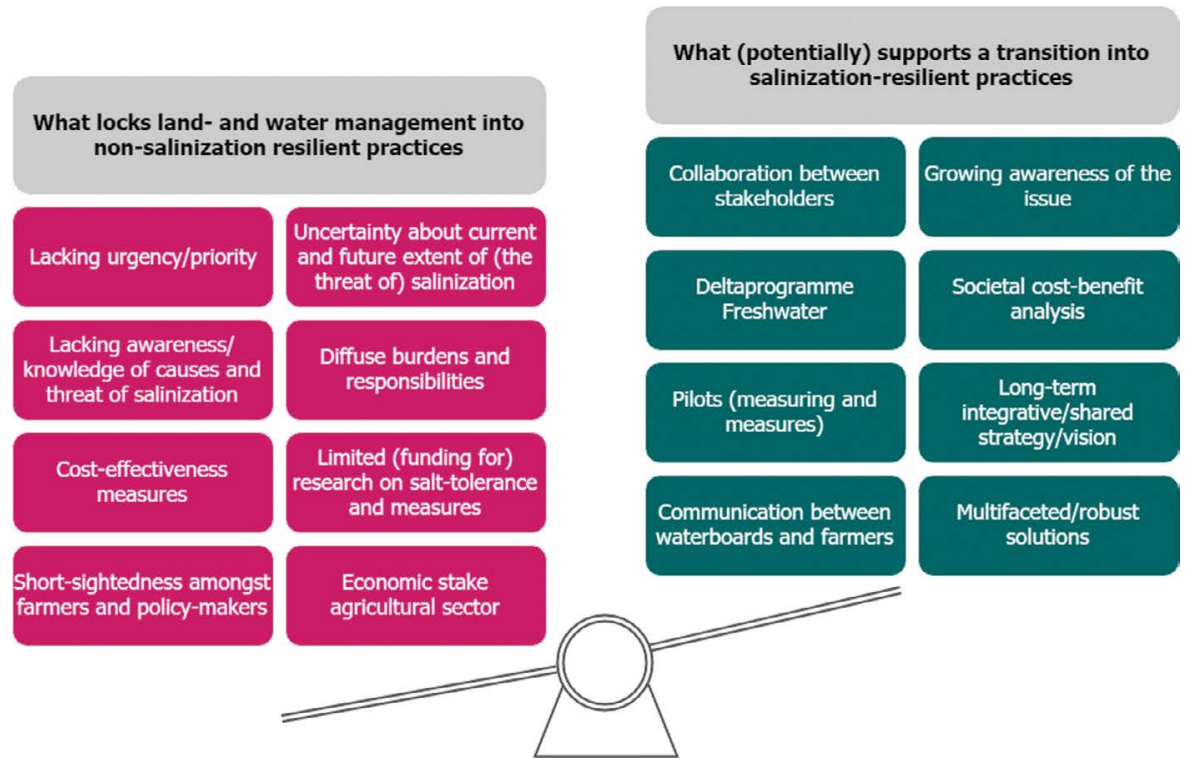

FIGURE 13.4 Key factors and actors involved in tipping the balance of factors that determine prevalent land- and water-management practices toward favoring salinization-resilient practices. (Adapted from Wigboldus et al., 2017.)

due to: (1) the lack of widespread (signaled) damage, (2) uncertainty about the extent of the issue in the (near) future, and (3) the priority of other issues. Closely related is the lacking of knowledge and awareness amongst farmers of the causes of salinization and their personal risk of salinization, which is largely preventing them from changing their current practices, as they: (1) are not aware of how their practices can induce salinization, (2) do not know if they should be taking measures, and (3) do not know what type of measures would be most effective. This also relates to the general uncertainty about the current and future extent of (the threat of) salinization as: (1) hardly any projections have been made of soil salinization, (2) salinization is a dynamic rather than a linear process, closely coupled to drought anomalies, and (3) there are large differences in expected salinization amongst the different climate change scenarios.

Another lock-in of the status quo is the limited available research on the salt-tolerance of commonly cultivated crops and soils specifically, which results in the widespread application of a precautionary principle, especially considering the financial risk a farmer would take. Moreover, the lack of funding for (practical) research and pilots, and subsequent limited knowledge on salt tolerance and measures is also locking-in current practices. This lack of funding can be tied back to the lacking sense of urgency, interest, and long-term perspective amongst policy-makers, and also the fact that it is difficult for a sector to invest collectively in a common issue when there is no or little collective research money, as this type of research is expensive, of long duration, and is in the interest of many (different) stakeholders.

Another lock-in is the economic stake of the agricultural sector in keeping certain practices and arrangements - like the flushing of the system based on the current 
chloride norms (or even lower) - in place, as they largely depend on such guarantees for their productivity and, therefore, profitability. This also leads to certain policies like 'function follows water' in spatial planning. Additionally, it makes certain rules and legislation, such as a prohibition for under-drainage or an obligation to install levelcontrolled drainage, politically sensitive/difficult. Although the economic stake of the agricultural sector could also be viewed as supportive in a transition to salinizationresilience - i.e. the future viability of an agricultural business depends on it - factors like focus on short-term gains and issues, lacking awareness/knowledge, uncertainty about the future threat of salinization, other priorities, but also the current uncertain cost-effectiveness or unprofitability of alternative measures are all reasons for not changing the status quo. The current lock-in can also be related to the diffusion of burdens, responsibilities, and even benefits, between farmers and waterboards (or society as the waterboard is financed through taxes). For instance, farmers are affected by salinization, both through brackish seepage in their parcels as well as in the ditches, and profit from the availability of freshwater, whereas the waterboards carry the responsibility of providing freshwater of a certain amount and quality. Moreover, as this creates a situation in which the (economic) incentives are not with one stakeholder, the (societal) cost-effectiveness of salinization-resilient measures for both farmers, as well as waterboards, is (even more) difficult to calculate or known to be negative.

\subsubsection{Main Opportunities for (More) Salinization-Resilience}

There are also factors that can support a transition into more salinization-resilient practices when they prevail over the lock-in factors (Figure 13.4). First of all, in recent years and especially after the summer of 2018, farmers and policy-makers have become increasingly aware of the issue of salinization, which has led to a growing interest in the topic, as evident from emerging measuring and monitoring projects and it being part of waterboard and provincial (development) programs. However, it is recognized that it takes more consecutive dry periods for salinization to become a more prominent issue. Nevertheless, projects in which farmers measure and monitor salinization at the parcel level and its effect amongst farmers can also aid in raising awareness. Furthermore, the Delta Programme Freshwater has opened up a window of opportunity for integrative, inter-stakeholder, and inter-regional addressing of freshwater issues, including salinization - although its share in the program is yet small. Another factor that is recognized by both experts and stakeholders to be crucial in stimulating this transition is more collaboration between the different stakeholders, i.e. the agricultural sector (e.g. LTO, KAVB), waterboards, provinces, and even the Ministries, Rijkswaterstaat, and knowledge institutes, as they all have a stake or (potential) role in addressing the issue, and need each other to successfully and sustainably address the issue. In the same line, increased communication between waterboards and farmers has already promoted more mutual understanding of each other's position and situation and helps in formulating an area-oriented approach. The latter is perceived to be very important by many of the interviewees, as the issue and therefore the possible solution(s) differ greatly with area. This also highlights the importance of involving multiple sectors, e.g. drinking water, industry, and nature, as they are often spatially mixed and have different interests, but could also work together on solutions. Furthermore, the majority of 
the interviewees call for the development of a long-term strategy, most logically on behalf of the province as this is already their formal role, but in collaboration and/ or consultation with the stakeholders, in order for both waterboards and farmers to know what to expect and incorporate this in their own policies/business operations, and also to ensure that no decisions are made or pilots are initiated that might turn out to be harmful (to others) or a waste of money. Nevertheless, pilots of innovative measures like Spaarwater (i.e. anti-salinization drainage and sub-soil storage) have helped with raising awareness about the issue of salinization, and also to show the positive effects of certain measures. As action-perspectives for farmers are currently limited, multi-faceted solutions, i.e. those that address multiple issues like flooding, nutrients, and drought, at once, increase the attractiveness of such measures; again, pilots can contribute to making the positive effects visible. Finally, although difficult, some sort of analysis of the (distribution of the) costs and benefits of different measures can aid in the decision-making as to what extent the issue should be dealt with collectively or individually.

\subsection{DISCUSSION}

The results of this study indicate that salinization is generally perceived as a threat for agriculture in the low-lying regions of the Netherlands and that the issue is desired to be addressed sooner rather than later. This perception is in line with scientific studies that show that the problem and risk of salinization in the low-lying regions of the Netherlands is widespread and growing (Voorde and Velstra, 2009; Velstra et al, 2009; Oude Essink et al., 2010; de Louw et al., 2010; OECD, 2014; ter Maat et al., 2014). Simultaneously, however, a sense of urgency seems to be lacking amongst the majority of farmers and policy-makers, which can be mainly explained by the limited awareness and recognition of the issue, the absence of widespread damage to date, and the priority of other issues. This is also reflected by the national Delta Programme, which mentions salinization only marginally, in contrast to the issue of drought, which is highlighted as the main threat to freshwater availability (Delta Commissioner, 2018b). Because the urgency to address freshwater availability and the issue of salinization is rather limited, dominant land- and water-practices amongst farmers, waterboards, and provinces - such as the focus on water drainage rather than retention, the flushing of the water system to meet chloride norms, and not accounting for the water situation in spatial planning - that can stimulate salinization, aggravate its negative consequences, or which cannot be sustained because of salinization, continue to prevail. This is despite research dating from a decade ago that has already shown that such water-management practices are unsustainable (Voorde and Velstra, 2009) and many studies since then that have identified possible adaptation and mitigation measures, ranging from drainage systems to increased salt tolerance, and from the parcel level to the headwater system (e.g. Snellen and van Hattum, 2012; de Louw and Bogaart, 2014; Friocourt et al., 2014; Oude Essink and de Louw, 2014; Delsman, 2015; de Vos et al., 2016; Stuyt et al., 2016).

While previous studies might give the impression that there are plenty of technological solutions to address the issue of salinization, this research shows that many of these measures are in a pioneering stage and that there is a significant knowledge 
gap in terms of their effectiveness, efficiency, and feasibility, which could also partly explain their limited adoption. Moreover, it should also be taken into account that regimes like the prevailing land and water practices have not been deliberately shaped, but are rather the outcome of path dependencies and developed interdependencies between actors and processes that have led to a state of being locked into a status quo (Holtz et al., 2008; Fünfshilling and Truffer, 2014). In this case, the (historical) widespread occurrence and severity of flooding problems amongst farmers, for example, can explain why there is a focus on water disposal rather than retention, as well as why water-related issues are often (preferred to be) solved collectively, e.g. by the waterboard, and on the basis of a solidarity principle (by use of taxes). In the same line, interdependencies that have been formed and institutionalized in the past, such as farmers being largely dependent on waterboards for the supply of sufficient freshwater - both in volume and in quality - and waterboards being largely dependent on provinces (e.g. through spatial planning) and the central government (e.g. through the distribution of water from the main water system) for the feasibility of meeting their 'effort obligations', have led to a situation in which burdens, benefits, and responsibilities are shared, and therefore no one has a strong incentive or complete power to change the status quo. Research on socio-technological transitions (e.g. Geels, 2002, 2011; Elzen et al., 2012) however, show that the gradual stress of climate change and salinization and sudden shocks like the extraordinarily dry summer of 2018 have the ability to disturb the current regime, as is evident from the growing attention to the issue and its increasing embeddedness in programs like the Delta Programme Freshwater. A regime change to (more) salinization-resilience can happen once transition-supporting factors prevail over lock-in factors (Wigboldus et al., 2016). This research shows that a coordinated, long-term collaborative interstakeholder strategy on salinization has the ability to stimulate this transition. To come to such a strategy, relevant stakeholders and experts should work together to identify all relevant aspects of the issue and develop a shared vision of the future. This should be possible considering that all of these stakeholders have the opportunity to organize themselves collectively and set the political-administrative agenda.

There are multiple limitations to the findings of this study. First of all, the selected interviewees do not completely represent the targeted stakeholder groups as: (1) the interviewees from the provinces and waterboards are the (senior) advisors and not the administrators/policy-makers themselves, and (2) the interviewees from the agricultural interest groups represent the interest of their constituents and not necessarily that of all farmers. Nevertheless, as the advisors do work closely with policy-makers and provide them with information and advice, they are aware of the political situation surrounding the issue and why it is on the agenda or not, and also have the ability to shape this agenda. Moreover, although it can be argued that the agricultural interest groups might be too conservative as their role is to protect the interests of their constituents, this is also exactly what makes them representative at large. Besides, including the innovative farmers should have compensated for a too conservative formulation of the issue, although the opinions and perceptions were often in accordance as the agricultural representatives were generally well aware of the many facets of the issue. Nevertheless, this research could be complemented by a large-scale survey amongst farmers to identify the current magnitude of the issue 
and the bottlenecks for farmers in addressing it. Another limitation of the research is that other sectors, e.g. industry, drinking water, and nature, were beyond the scope of the research, whereas their stake in the issue does have implications for the possibilities of certain measures (and the other way around) especially considering that these functions are often spatially mixed. Furthermore, as there was no list of pertinent issues regarding the topic of salinization in the Netherlands, the analysis might be incomplete despite the large number of interviews. Nevertheless, as the aim of the study was to provide an initial wide-ranging assessment, the results can be used for a more focused analysis of selected aspects that are deemed most pertinent by this research. Finally, the results highlight a knowledge gap in the effectiveness, efficiency, and feasibility of different measures, that should be addressed by future research. Preferably, this is complemented by a societal cost-benefit analysis to inform stakeholders about the different possible pathways to salinization-resilience.

\subsection{CONCLUSION}

This research aimed to identify how the Dutch agricultural sector can be made more salinization-resilient, by reviewing the extent to which salinization is already perceived as an issue, how the dominant land and water practices relate to the issue of salinization, the opportunities and barriers of different mitigation and adaptation measures in addressing the issue, and what is generally preventing a transition toward salinization-resilience and the opportunities to stimulate such a transition. Based on the interviews with experts, agricultural representatives, waterboards, provinces, and innovative farmers, it can be concluded that salinization is perceived as a large threat to agriculture in the low-lying regions of the Netherlands that should be addressed sooner rather than later, but that the urgency to do so is lacking due to low recognition and awareness of the issue amongst policy-makers and farmers, as well as the priority of other issues. Moreover, it can be concluded that current dominant land- and water-management practices like the focus on disposing water instead of retaining it, the lacking efficiency in the use and supply of freshwater, and the paradigm of 'water follows function' in spatial planning and chloride norms are largely stimulating salinization and/or are expected to become unsustainable in light of salinization. Furthermore, the opportunities and barriers of different mitigation and adaptation measures like anti-salinization drainage, a higher water level, soil conservation, more efficient water use and supply are that they often have other positive side-effects and/or are not too different from current practices, thereby relatively attractive to implement, but that these are not expected to be effective on the long-term and that their (cost-) effectiveness is still rather unknown. For salt-tolerant agriculture, the opportunities lie with the selection of more salt-tolerant cash crops, and although this could be a more long-term solution, the salt-tolerance of these crops and common soils is currently under-researched. For spatial differentiation of water prices and in functions, the opportunities are that this can respectively increase efficiency in use and supply, as well as secure enough freshwater for certain areas. Nevertheless, such measures are politically challenging and might take a long time to become the standard. A lock-in of the status quo is that the diffuse burdens and responsibilities between farmers and water managers are resulting in virtually 
no one having a strong incentive nor power to change the status quo. Moreover, the lacking long-term perspective amongst stakeholders and the uncertainty about the effectiveness and efficiency of different measures are preventing a transition to salinization-resilience. On the other hand, especially more communication and collaboration between the stakeholders can create opportunities for such a transition. Furthermore, it is strongly advised that more research is done on the effectiveness of different mitigation and adaptation solutions, as this is currently lacking and thereby limiting the action-perspectives for both farmers as well as water managers. Finally, it is advised that such research be supplemented by a societal cost-benefit analysis to identify the societal cost-effectiveness of different measures and the distributions of the costs and benefits, thereby informing decision-making on a preferred strategy.

\section{ENDNOTES}

1. In this research, salinization-resilience entails the ability to sustainably cope with, prevent or limit salinization-related stressors.

2. Note that the classes are skewed to the left, which is to account for incompleteness of answers on all the semi-structured questions, as not all stakeholders (e.g. innovative farmers) were able to answer every question.

\section{REFERENCES}

de Louw, P. G. B. 2013. "Saline seepage in deltaic areas: Preferential groundwater discharge through boils and interactions between thin rainwater lenses and upward saline seepage". Doctoral dissertation. Amsterdam: Vrije Universiteit.

de Louw, P. G. B., and Bogaart, P. 2014. Rainwater lenses. Amersfoort: STOWA. https:// www.stowa.nl/deltafacts/zoetwatervoorziening/delta-facts-english-versions/rainwaterlenses (Accessed May 28).

de Louw, P. G. B., Essink, G. O., Stuyfzand, P. J., and Van der Zee, S. E. A. T. M. 2010. "Upward groundwater flow in boils as the dominant mechanism of salinization in deep polders, The Netherlands". Journal of hydrology 394, no. 3-4: 494-506.

de Vos, A., Bruning, B., van Straten, G., Oosterbaan, R., Rozema, J., and van Bodegom, P. 2016. Crop salt tolerance under controlled field conditions in the Netherlands, based on trials conducted at Salt Farm Texel. Texel: Salt Farm Foundation.

Delsman, J. R. 2015. "Saline groundwater-Surface water interaction in coastal lowlands". Doctoral dissertation. Amsterdam: Vrije Universiteit.

Delta Commissioner. 2018a. Leren van de droogteperiode 2018. Deltanieuws, 5. https:// magazines.deltacommissaris.nl/deltanieuws/2018/05/zoet-water

Delta Commissioner. 2018b. Delta programme 2019. Continuing the work on the delta: Adapting the Netherlands to climate change in time. The Hague: Rijksoverheid.

Elzen, B., Barbier, M., Cerf, M., and Grin, J. 2012. Stimulating transitions towards sustainable farming systems. Farming Systems Research into the 21st century: The new dynamic (pp. 431-455). Dordrecht: Springer.

Friocourt, Y., Kuijper, K., and Leung, N. 2014. Salt intrusion. Amersfoort: STOWA. https:// www.stowa.nl/deltafacts/zoetwatervoorziening/delta-facts-english-versions/saltintrusion (Accessed May 28, 2019)

Fünfschilling, L., and Truffer, B. 2014. "The structuration of socio-technical regimesConceptual foundations from institutional theory." Research policy 43, no. 4: 772-791.

Geels, F. W. 2002. "Technological transitions as evolutionary reconfiguration processes: a multi-level perspective and a case-study." Research policy 31, no. 8-9: 1257-1274. 
Geels, F. W. 2011. "The multi-level perspective on sustainability transitions: Responses to seven criticisms." Environmental innovation and societal transitions 1, no. 1: 24-40.

Ghassemi, F., Jakeman, A. J., and Nix, H. A. 1995. Salinisation of land and water resources: human causes, extent, management and case studies. Wallingford: CAB international.

Holtz, G., Brugnach, M., and Pahl-Wostl, C. 2008. "Specifying "regime"-A framework for defining and describing regimes in transition research." Technological forecasting and social change 75, no. 5: 623-643.

Huisman, P., Cramer, W., Van Ee, G., Hooghart, J. C., Salz, H., and Zuidema, F. C. 1998. Water in the Netherlands. Rotterdam: Netherlands Hydrological Society.

Maas, E. V., and Hoffman, G. J. 1977. "Crop salt tolerance-current assessment." Journal of the irrigation and drainage division 103, no. 2: 115-134.

OECD. 2014. Water governance in the Netherlands: Fit for the future? OECD studies on water. Paris: OECD Publishing.

Oude Essink, G., and Louw, P. D. 2014. Brackish seepage. Amersfoort: STOWA. https:// www.stowa.nl/deltafacts/zoetwatervoorziening/delta-facts-english-versions/brackishseepage\#1572 (Accessed May 28, 2019).

Oude Essink, G. H. P., Van Baaren, E. S., and De Louw, P. G. 2010. "Effects of climate change on coastal groundwater systems: A modelling study in the Netherlands." Water resources research 46 , no. 10.

Qadir, M., and Oster, J. D. 2004. "Crop and irrigation management strategies for saline-sodic soils and waters aimed at environmentally sustainable agriculture." Science of the total environment, 323, no. 1-3: 1-19.

Qadir, M., Quillérou, E., Nangia, V., Murtaza, G., Singh, M., Thomas, R. J., et al. 2014. "Economics of salt-induced land degradation and restoration." Natural resources forum 38, no. 4: 282-295.

Reed, M. S., Graves, A., Dandy, N., Posthumus, H., Hubacek, K., Morris, J., et al. 2009. "Who's in and why? A typology of stakeholder analysis methods for natural resource management." Journal of environmental management 90, no. 5: 1933-1949.

Shahid, S. A., Zaman, M., \& Heng, L. 2018. Soil salinity: historical perspectives and a world overview of the problem. In Guideline for salinity assessment, mitigation and adaptation using nuclear and related techniques (pp. 43-53). Cham: Springer.

Singh, A. 2015. "Soil salinization and waterlogging: A threat to environment and agricultural sustainability." Ecological indicators 57: 128-130.

Snellen, B., and van Hattum, T. 2012. Soil as a buffer. Amersfoort: STOWA. https://www. stowa.nl/deltafacts/zoetwatervoorziening/delta-facts-english-versions/soil-buffer (Accessed May 28, 2019).

Stuyt, L. C. P. M., Blom-Zandstra, M., and Kselik, R. A. L. 2016. Inventarisatie en analyse zouttolerantie van landbouwgewassen op basis van bestaande gegevens. Report no. 2739). Wageningen: Wageningen Environmental Research.

ter Maat, J., Haasnoot, M., Hunink, J., van der Vat, M. 2014. Effecten van maatregelen voor de zoetwatervoorziening in Nederland in de 21 eeuw. Report no. 1209141-000. Delft: Deltares.

Voorde, J., and Velstra., J. 2009. Leven met zout water: overzicht huidige kennis omtrent interne verzilting. Gouda: Acacia Water, Leven met Water, and STOWA.

Velstra J., Hoogmoed M., and Groen K. 2009. Inventarisatie maatregelen omtrent interne verzilting. In Leven met zout water. Gouda: Acacia water.

Wigboldus, S., Klerkx, L., Leeuwis, C., Schut, M., Muilerman, S., and Jochemsen, H. 2016. "Systemic perspectives on scaling agricultural innovations. A review." Agronomy for sustainable development 36, no. 3: 46.

Wigboldus, S., Hammond, J., Xu, J., Yi, Z. F., He, J., Klerkx, L., and Leeuwis, C. 2017. "Scaling green rubber cultivation in Southwest China-An integrative analysis of stakeholder perspectives." Science of the total environment 580: 1475-1482. 